\title{
A new dimension in the dental rehabilitation of hereditary ectodermal dysplasia
}

\author{
Prashant Raktade ${ }^{1}$, Snehal Prashant Raktade ${ }^{2}$, Suday Rajurkar ${ }^{3, *}$, Neha Joshi ${ }^{4}$, Kanchan Shah ${ }^{5}$ \\ ${ }^{1,4,5}$ Associate Professor, ${ }^{2}$ Prosthodontist, ${ }^{3}$ Assistant Professor, ${ }^{1,3,5}$ Dept of Oral and Maxillofacial Surgery, ${ }^{2}$ Dept. of \\ Prosthodontics, ${ }^{4}$ Dept of Pediatric and Preventive Dentistry, ${ }^{\mathbf{1}, \mathbf{3}}$ Government Dental College and Hospital, Aurangabad \\ Maharashtra, ${ }^{2}$ Identist Dental Clinic, Aurangabad Maharashtra, ${ }^{4}$ Pandit Deendayal Upadhayay Dental College and Hospital, \\ Solapur Maharashtra, India
}

*Corresponding Author:

Email: suday.rajkumar@gmail.com

\begin{abstract}
Partial or complete anodontia is one of the major dental findings in a patient of Hereditary Ectodermal Dysplasia (HED) and is diagnosed at a young age when the parents are concerned about the child's functional needs and esthetic appearance. The oral rehabilitation of these cases is often very challenging. Removable partial and complete dentures are most commonly used treatment modalities for such patients. Although implants and implant supported dentures can be considered, age is one of the compromising factors for placement of implants in young patients due to the possibility of impending growth of jaws. We present here a case of 3 and a half year old male patient of HED treated successfully with implants. With a long term follow up of 6 years, we achieved excellent functional and esthetic results thereby boosting the self-confidence of the child.
\end{abstract}

Keywords: Hereditary ectodermal dysplasia, Anodontia, Dental implants.

\section{Introduction}

The term Ectodermal Dysplasia was coined by Weech in $1929 .{ }^{1}$ Hereditary ectodermal dysplasia (HED) is an inherited disorder characterized by abnormal development of embryonic ectodermal derived organs including teeth, nails, hair (alopecia or hypotrichosis) and sweat glands (lack of sweat glands). ${ }^{2}$ The dental findings in patients of HED include anodontia or hypodontia of the primary and/or permanent teeth, hypoplastic conical teeth, and underdevelopment of the alveolar ridges. The affected patients need dental prosthetic treatments during their developmental years. The options for a definitive treatment plan include fixed, removable or implant-supported prostheses, singly or in combination. $^{3}$ This clinical report describes the prosthetic rehabilitation of a pediatric patient with hereditary ectodermal dysplasia treated with maxillary removable partial denture and mandibular implant supported over-denture.

\section{Case Report}

A 3 and half year old male child reported with completely edentulous mandibular arch and peg shaped deciduous central incisors and bilateral deciduous second molars in maxillary arch. Patient had previously visited many dental clinics with a complaint of absence of teeth and functional impairment such as difficulty in chewing and was treated using maxillary removable partial denture and mandibular complete denture which were very ill fitting. Also the anatomy of the teeth used in those dentures did not resemble deciduous teeth. General physical examination of the patient revealed an overall senile appearance characterized by flaky hair, dry scalp, saddle nose, seborrheic dermatitis. Patient was diagnosed with Hereditary Ectodermal Dysplasia based on all the above mentioned clinical findings. Cone beam computed tomography (CBCT) of the patient revealed peg shaped maxillary deciduous central incisors above which successors- peg shaped permanent tooth buds were seen bilateral deciduous second molars were also seen. No other permanent tooth buds were seen in maxillary arch. In mandible, tooth buds of permanent first molars were seen. The child's parents were counseled regarding the diagnosis of the patient; the proposed treatment plan and the need for a long term follow up was explained. Patient was advised a series of investigations and was planned for maxillary removable partial denture and mandibular implant supported over denture under general anesthesia.

Before taking the patient under general anesthesia prior to placement of implants, following steps were carried out:

1. Maxillary/Mandibular jaw models of child

2. Maxillary/Mandibular jaw models of peer child with all 20 decidous teeth to facilitate replication of teeth anatomy.

3. Maxillary/Mandibular special trays for making a final impression.

4. Maxillary/Mandibular jaw relation record base fabrication.

5. Pulpectomy followed by tooth preparation of maxillary deciduous central incisors was done to use them as an abutment.

As seen on CBCT, the bone height and width in the interforaminal region was inadequate for implant placement. Hence ridge splitting was planned to achieve width for placement of implant.

After inducing general anesthesia, two MS Osstem $^{\mathrm{TM}}(2.2 \times 10 \mathrm{~mm})$ one piece fixtures with ball abutments was placed in mandibular interforaminal region. Good torque of $>35 \mathrm{ncm}$ was obtained. After placement of implants, following steps were carried out: 
1. Maxillary and mandibular final impressions were made in Aquaseal ${ }^{\mathrm{TM}}$ Putty.

2. Centric bite recorded using previously prepared record bases.

3. A wax try-in of teeth arrangement was done within a week.

An acrylic BPS ${ }^{\mathrm{TM}}$ maxillary horse shoe shaped removable partial denture using central incisors as abutment, completely encircling the second molars was used to relieve the soft palate areas and avoid gag reflexes. Mandibular denture was retained with $6 \mathrm{ncm}$ "O" rings. Initially for few days, patient had difficulty in retention of maxillary denture; so to improve the stability soft tissue reliner was used which drastically improved the stability. Later child got aquainted with dentition. Patient is kept under regular follow up for 6 years.

\section{Discussion}

First description of HED was given by Thurman. ${ }^{4-6}$ HED can be classified clinically into two main formsHypohydrotic form Christ Seimens-Tourian Syndrome a triad of hypohidrosis, hypotrichosis and hypodontia in which $\mathrm{X}$ linked recessive pattern of inheritence is seen. The other form is Hydrotic form Clouston syndrome in which hair and nails are affected; sweat glands are spared and inherited as an autosomal dominant trait. ${ }^{7}$ The oral rehabilitation of patients of HED proves to be a challenging task and is a multi-staged procedure. Mostly removable partial or complete dentures or implant supported over-dentures have been used. The retention/stability problems encountered with removable partial or complete dentures arise due to low vestibular depth, lack of alveolar bone height, sharp and thin alveolar ridge and growing age of the child which demands repeated relining and rebasing of the dentures. Also over the time, due to resorption of alveolar ridge, the denture borders become ill fitting and tend to accumulate debris. The masticatory efficacy with removable prosthesis is relatively low. Due to constant pressure on the bone there is an increased resorption of the alveolar bone. ${ }^{8}$ Implants have been thought to have a negative effect on growth of jaws in pediatric patients. ${ }^{9}$ So as per previous literature, cases of HED had been treated by removable or complete dentures.Safe site for implant placement is interforaminal region. Placement of implants in a case with lack of height and width of alveolar bone needs either ridge split or bone grafting (vertical or horizontal). ${ }^{10}$ Using dental implants has an advantage of better retention and masticatory efficacy, early acquaintance of patient to the denture and good labial support in comparison to removable or complete dentures. As growth occurs, interimplant distance increases approximately 1-2 mm per year. ${ }^{11}$ In our case increase in the transverse width of mandible was a phenomemon due to which pressure on the metal housing and $\mathrm{O}$ rings subsequently increased and was an endangering condition for implants as well. Every year the dentures needed to be relined because of excessive resorption of "O" rings as well as head of the ball abutments. So $\mathrm{O}$ rings needed to be replaced periodically. Initially, the $\mathrm{O}$ rings were replaced every six months along with the changed positions of the metal housings. New holes were made in the denture for attaching the female component for initial 1 year of follow up. Later new set of dentures were fabricated along with new metal housing and "O" rings every year. In this tenure, four new sets of dentures have been given to avoid excessive wear of ball abutment heads caused by increased transverse width of the mandible. Literature reports that implant placement hampers mandibular growth. ${ }^{12,13}$ In the above mentioned case report, there was a definite increase in the transverse width of the mandible which needed repeated adjustments in the dentures. But transverse and vertical growth of the mandible was unhampered. Patient got aquainted with dentures at an early age; good compliance was obtained from patient. Excellent oral hygiene was maintained by the patient. Dentures were semifixed so the masticatory efficacy was good. With implant supported overdentures, excellent labial support was obtained. This boosted the self-confidence of the patient. By use of implants, functional needs of the patient could be met because of two stable points ahead of mental foramen. Placement of implants and teeth for function and aesthetics definitely improved the general condition and overall growth of the patient.

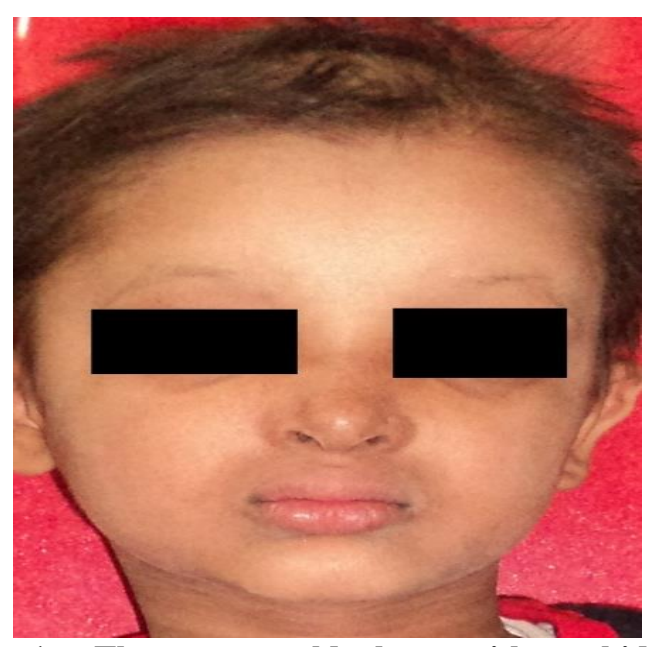

Fig. 1: Three-year old boy with anhidrotic ectodermal dysplasia

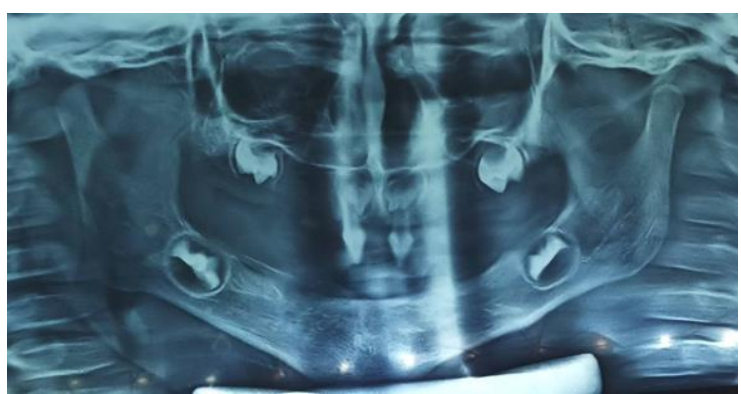

Fig. 2: Preoperative panoramic radiograph 


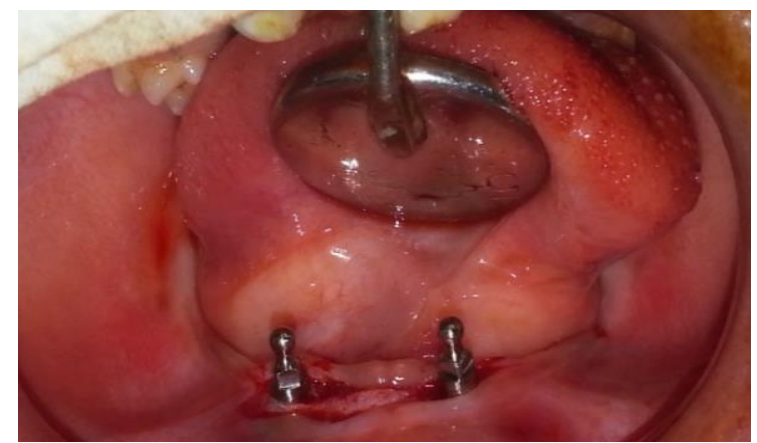

Fig. 3: Intraoperative image showing 2.2x10mm MS Ostem ${ }^{\mathrm{TM}}$ Single piece implants in position

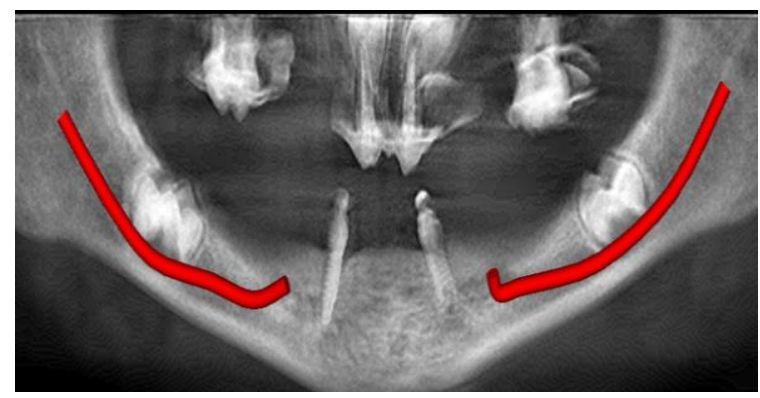

Fig. 4: 3 year post-operative follow-up

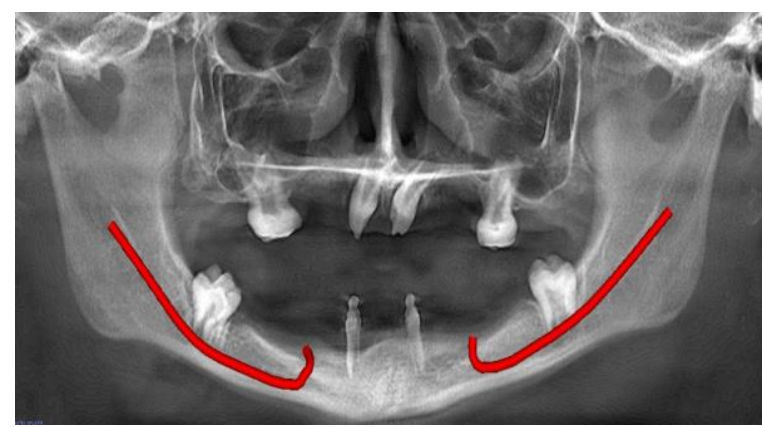

Fig. 5: 6 year post-operative follow-up

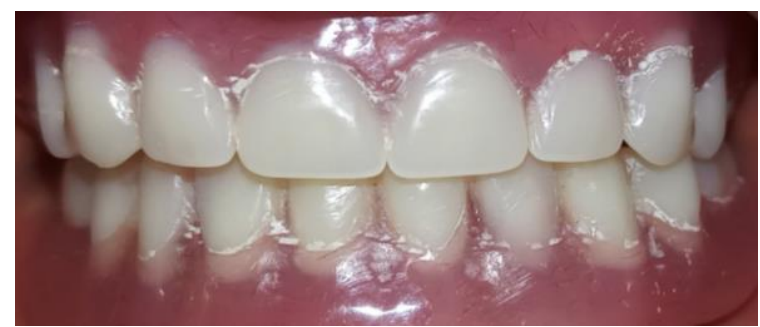

Fig. 6: Post-operative clinical photograph of 6 years of follow-up

\section{Conclusion}

We would like to conclude that implant supported over dentures can be a considered a viable option in HED patients as it helps to rehabilitate patients at younger age; though a keen surgical approach is required to place implants away from mental foramen. Repeated adjustments in the dentures are required to provide functionally stable occlusion. We have been following the case till date since 6 years. Long term follow up and good patient compliance is an imperative factor determining the success of such cases.

\section{Funding: None}

\section{Conflict of Interest: None}

\section{Informed Consent: Consents obtained}

\section{References}

1. Weech AA. Hereditary ectodermal dysplasia(congenital ectodermal defect). Am J Dis Child. 1929;37:766-90.

2. Paschos E, Huth K.C, Hickel R. Clinical management of hypohidrotic ectodermal dysplasia with anodontia: Casei report. J Clin. Pediatric Dent. 2002;27(1):5-8

3. Oliver R.D, Fye WN, Hal in Ja, Steiner JF. Prosthetic management in anhidrotic ectodermal dysplasia patient. report of a case. J Dent Children. 1975;43:375-78

4. Nunn JH, Carter NE, Gillgrass TJ, Hobson RS, Jepson $\mathrm{NJ}$, Meechan JG et al. The interdisciplinary management of hypodontia: background \& role of paediatric dentistry.Br. Dent. J. 2003;194:245-51.

5. Early prosthetic treatment of patients with Ectodermal dysplasia: a clinical report. Tarjan I, Gabris K, Rozsa N. $J$ Prosthet Dent. 2005;93:419-24.

6. Ammanagi R, Keluskar V, Bagewadi A. Ectodermal dysplasia :Report and analysis of eleven south Indian patients with review of literature. J Ind Acad Oral Med Rad. 2010;22:93-98.

7. The effect of removable partial dentures on alveolar bone resorption: a retrospective study with Cone beam computed tomography. Ozan et al. J. Prosthodont. 2013.

8. Guckas AD, Brahim JS, McLarthy GR, Rudy SF, Cooper LJ. Using endosseous implants for patients with ectodermal dysplasia. J. Am Dent Assoc.1991:122(10):5962.

9. Parthiban PS, Lakshmi R V, Mahendra J, Shreekumar K, Namasivayam A. A contemporary approach for treatment planning of horizontally resorbed alveolar ridge: Ridge split technique with simultaneous implant placement using platelet rich fibrin membrane application in mandibular anterior region. Indian J Dent Res. 2017;28;109-13.

10. Kramer F.J, Baethge C, Tschernitschch H. Implants in children with ectodermal dysplasia: a case report \& literature review. $\mathrm{Cl}$ in oral Implants. Res. 2007;18(1)140-46.

11. Hall K.R. Pediatric orofacial medicine and pathology. Fourth Edition, London. Chapman \& Hall. 1994:163.

12. Cronin RJ. Implant use in growing patients. Treatment planning concerns. Dent Clin North Am. 1998;42(1):1-34.

How to cite this article: Raktade $\mathrm{P}$, Raktade $\mathrm{S}$ P, Rajurkar S, Joshi N, Shah K. A new dimension in the dental rehabilitation of hereditary ectodermal dysplasia. Int J Periodontol Implantol. 2018;3(4):140-142. 